\title{
Transformações agrárias em Mato Grosso (Brasil): um olhar a partir dos Censos Agropecuários (1940-2006)
}

\author{
VALDEMAR JoÃo WeSZ JUNIOR
}

PALAVRAS-CHAVE: transformações agrárias, Mato Grosso, políticas públicas, Censo Agropecuário.

\section{CÓDIGOS JEL: N56, Q15, Q18, R30.}


estado de Mato Grosso está localizado na região Centro-Oeste do Brasil e, atualmente, assume grande protagonismo na produção agropecuária nacional. O objetivo deste artigo é analisar as transformações agrárias que ocorreram em Mato Grosso, focalizando no periodo de 1940 a 2006. Para tanto, foi realizada uma revisão bibliográfica e análise estatística a partir dos Censos Agropecuários disponiveis entre 1940 e 2006. Os resultados apontam para a importância que um conjunto bastante amplo de políticas públicas teve sobre o espaço rural mato-grossense, que se refletiram no forte aumento no número de estabelecimentos agropecuários, ampliação das superficies utilizadas, crescimento das áreas de lavouras e pastagens, mudanças nos principais cultivos agrícolas e introdução de um novo padrão de produção. Apesar destas transformações, Mato Grosso segue apresentando uma fortíssima concentração na posse da terra. 


\title{
Agricultural transformation in Mato Grosso (Brazil): a view based on the Agricultural Census (1940 - 2006)
}

\section{KEYWORDS: agricultural transformation, Mato Grosso, public po- licies, agricultural census.}

\author{
JEL CODES: N56, Q15, Q18, R30.
}

The aim of this article is to analyze the agricultural transformations that oc-
curred in Mato Grosso, particularly in the period that spans from 1940 to
2006. A literature review and an analysis of the agricultural census statistics available between the dates indicated show the effects that a wide range of public policies had in rural areas of Mato Grosso. These include a sharp increase in the number of farms, the expansion of land usage, increased crop and grazing areas, along with changes in key crops and the introduction of a new production model. Despite these transformations, the state of Mato Grosso-located in the Midwest region of Brazil and currently a major domestic agricultural producer-still exhibits a strong concentration of land ownership.

Recepção: 2016-02-03 - Revisão: 2016-07-13 - Aceitação: 2016-09-05

Valdemar João Wesz Junior é professor adjunto da Universidade Federal da Integração Latino-Americana (UNILA) e pesquisador do Grupo de Estudo em Mudanças Sociais, Agronegócio e Políticas Públicas (GEMAP). Doutor e mestre pelo Programa de Pós-Graduação de Ciências Sociais em Desenvolvimento, Agricultura e Sociedade na Universidade Federal Rural do Rio de faneiro (CPDA/UFRRf). Endereço para correspondência: Rua Castelo Branco, 107, apto. 306, Vila Maracanã, 85852-010 Foz do Iguaçu (Paraná, Brasil).E-mail:jwesz@yahoo.com.br 


\section{INTRODUÇÃO}

O estado de Mato Grosso está localizado na região Centro-Oeste do Brasil e possui uma área de $903.366 \mathrm{~km}^{2}$ (equivalente à soma do território da França e da Alemanha) (Figura 1). Está organizado em cinco mesorregiões, 22 microrregiões e 141 municípios, cuja capital é Cuiabá. Contém três biomas (cerrado [39\% da superfície], floresta amazônica [54\%] e pantanal [7\%]) e consta de três unidades geomorfológicas: planaltos, depressões e planícies (IBGE, 2014).

Mato Grosso, atualmente, tem sido qualificado por alguns acadêmicos, gestores públicos, meios de comunicação e atores locais como a fazenda do Brasil (ou do mundo, para os mais otimistas), dada a grande disponibilidade de recursos naturais, condições edafoclimáticas favoráveis, uso intenso de inovações tecnológicas e elevada produtividade. Em nível nacional, tornou-se líder na produção de soja (produto agropecuário de maior importância econômica do país), algodão, girassol e milho segunda safra, além de deter o maior rebanho bovino do Brasil (MAPA, 2014).

É importante ressaltar que esse protagonismo ocorreu de modo extremamente rápido, fruto de transformações profundas que tiveram início na segunda metade do século $\mathrm{xX}$ a partir de inúmeras iniciativas de expansão da fronteira ${ }^{1}$. Até 1940, por exemplo, existiam apenas 14 municípios no que atualmente compreende o estado de Mato Grosso, a população recenseada era inferior a 200 mil habitantes (75\% residia no espaço rural) e o Produto Interno Bruto (PIB) era muito modesto, abaixo dos $\mathrm{R} \$ 50$ milhões (valores constantes em reais de 2000), crescendo na metade da velocidade nacional. Atualmente o cenário difere-se completamente: o número de municípios ampliou 10 vezes; a população superou os três milhões em 2010, com apenas 18\% residindo no espaço rural; o PIB alcançou $R \$ 30$ bilhões em 2011 (valores constantes em reais de 2000), com um crescimento de $12,6 \%$ entre 2010 e 2011 (melhor resultado entre todos os estados brasileiros) (IBGE, 2014) ${ }^{2}$.

1. O tema do avanço da fronteira foi amplamente comentado no Brasil, tanto pelos representantes do setor agropecuário quanto por alguns acadêmicos. Contudo, como bem argumenta BERNARDES (2006), é preciso ponderar que, no caso de Mato Grosso, não se trata de um avanço sobre terras vazias, onde os pioneiros fizeram a ponte entre o mundo selvagem e a civilização, levando o progresso. Ao contrário disso, havia indígenas, posseiros, garimpeiros, seringueiros, etc. Nesse sentido, é interessante a contribuição de MARTINS (1996), que argumenta que o avanço da fronteira caracteriza-se pela nova racionalidade econômica, pela constituição formal e institucional de novas mediações políticas, pela expansão dos mercados e pela introdução de novas concepções de vida.

2. Para um maior detalhamento, consultar SiqueIRA (2002), RAVACHE (2013), WeSz JR. (2014), entre outros. 
As mudanças também ocorreram no espaço rural, com intensas transformações no número de estabelecimentos agropecuários, na área total das explorações rurais, na condição do produtor, na composição fundiária e nas atividades agropecuárias. A compreensão desses processos torna-se pertinente em um estado onde a produção agropecuária exerce grande relevância: em 2011, Mato Grosso foi a federação com maior percentual do PIB advindo da agropecuária (22\%), enquanto o segundo colocado (Rondônia) ficou com $18 \%$ e o Brasil com apenas 5,5\% de média nacional no mesmo ano (IBGE, 2014).

O objetivo deste artigo é analisar as transformações agrárias que ocorreram no estado de Mato Grosso de 1940 em diante, visto que foi a partir deste momento que se implementaram diferentes políticas públicas para as regiões da floresta amazônica e do cerrado, que afetaram diretamente o espaço rural mato-grossense. Para tanto, foi realizada uma ampla revisão bibliográfica e análise estatística a partir dos dados dos Censos Agropecuários disponíveis a partir de 1940.

\section{FIGURA 1}

\section{Localização de Mato Grosso}


$\downarrow$ Cuiabá (capital)

Limites municipais

Principais rodovias

Fonte: elaboração própria, IBGE (2014). 
Apesar de Rondônia e Mato Grosso do Sul terem desmembrado-se de Mato Grosso em 1944 e 1977, respectivamente, neste trabalho foi respeitada a abrangência territorial do atual estado de Mato Grosso, mesmo para períodos anteriores. Para tanto, os dados dos Censos Agropecuários foram recalculados para manter a mesma unidade de referência, sendo considerados apenas os municípios/zonas/microrregiões que pertenciam ao recorte espacial em vigor ${ }^{3}$.

No próximo item, apresentam-se os mecanismos de acesso a terra e as principais atividades econômicas presentes em Mato Grosso até 1940. Na sequencia, discutem-se as políticas públicas de ocupação que foram implementadas no estado. Em seguida, analisam-se as transformações agrárias que ocorreram em Mato Grosso entre 1940 e 2006, baseando-se principalmente nos Censos Agropecuários. Por fim, são resgatados alguns elementos conclusivos do estudo.

\section{ATIVIDADES ECONÔMICAS E POSSE DA TERRA EM MATO GROSSO ATÉ 1940: UM BREVE RESGATE}

A Capitania de Mato Grosso foi criada em 1748, em uma área que até então era considerada de domínio da Coroa espanhola, segundo o Tratado de Tordesilhas. Procurando garantir o direito das terras recém-ocupadas pelos portugueses, o então governador Antonio Rolim de Moura criou a vila deVila Bela da Santíssima Trindade, localizada na fronteira Oeste e transformada em capital da Província (a capital foi transferida para Cuiabá somente em 1824). Em 1750, o Tratado de Madri reconheceu a Capitania de Mato Grosso como território português, em uma área de aproximadamente 1,5 milhões de $\mathrm{km}^{2}$ (que abrange os atuais estados de Mato Grosso, Mato Grosso do Sul e Rondônia). Com a constituição do Império, o nome foi alterado para Província de Mato Grosso em 1824, mantendo a mesma área até o desmembramento do atual estado de Rondônia e do estado de Mato Grosso do Sul (Siqueira, 2002).

3. Em 1940 os dados foram baseados nos municípios de Alto Araguaia, Alto Madeira (atual Aripuanã), Araguaiana (atual Barra do Garças), Cáceres, Cuiabá, Diamantino, Lajeado (atual Guiratinga), Mato Grosso (atual Vila Bela da Santíssima Trindade), Livramento (atual Nossa Senhora do Livramento), Poconé, Poxoréu, Rosário Oeste e Santo Antônio (atual Santo Antônio do Leverger). Em 1950 foram utilizadas: Zona Aripuanã, Zona de Chapada, Zona Leste, Zona da Encosta e Zona Pantanal (menos os municípios de Aquidauana e Corumbá, pertencentes ao atual Mato Grosso do Sul). Em 1960 o recorte seguiu a Zona de Aripuanã, Zona da Chapada, Zona de Poxoréu (Leste), Zona da Encosta Norte e Zona da Baixada Norte. Em 1970 foram consideradas as microrregiões: Alto Guaporé-Jauru, Alto Paraguai, Baixada Cuiabana, Garças, Norte Mato-Grossense e Rondonópolis. Nos registros de 1975, ainda que a divisão entre Mato Grosso e Mato Grosso do Sul não estivesse efetivada (o que ocorreu formalmente em 1977), os dados já foram apresentados em separado. 
A formação da Capitania de Mato Grosso está associada à descoberta, em 1719, de lavras de ouro nos rios Coxipó e Córrego da Prainha, formadores do rio Cuiabá. O enfraquecimento destas minas promoveu a abertura de novas frentes de mineração na região do Guaporé. Próximo aos garimpos, algumas áreas foram ocupadas - por meio de Cartas de Sesmarias- para a criação de gado e produção de alimentos, suprindo, parcialmente, as demandas dos núcleos de mineração (Fernández, 2007; Higa, 2005).

A queda da produção de minérios e o isolamento de outras províncias e do mercado internacional resultaram em uma estagnação econômica da região. Mas, com o fim da guerra do Paraguai em 1870, o transporte fluvial pelo rio Paraguai foi retomado e a província de Mato Grosso passou a importar produtos industrializados e exportar matérias-primas. Entre os produtos agropecuários de maior expressividade econômica, destacava-se a pecuária bovina e o cultivo da cana-de-açúcar. Da cana era produzido o açúcar, a rapadura, o álcool e a aguardente, que inicialmente atendiam ao consumo nos garimpos, mas em seguida passaram a abastecer os núcleos urbanos que se formavam (Cuiabá,Vila Bela, Cáceres, Chapada e Santo Antonio do Leverger), além de ser exportada. Também compunham as atividades econômicas de Mato Grosso a extração de madeira, seringa, erva-mate, poaia ${ }^{4}$ e látex (borracha), que se concentrava principalmente nas matas ciliares e na floresta amazônica (Fernández, 2007; Siqueira, 2002).

Em suma, do período colonial até o início do século $\mathrm{xx}$, as principais atividades econômicas de Mato Grosso estiveram associadas, predominantemente, ao extrativismo mineral (ouro, diamante, etc.) e vegetal (madeira, erva-mate, poaia e látex), ao uso de pastagens nativas para pecuária (localizadas na baixada cuiabana e nas bacias do Pantanal, Guaporé e Araguaia) e ao desenvolvimento de lavouras em áreas de maior fertilidade natural, próximas aos canais de navegação, como no caso da produção de cana-de-açúcar para os engenhos (situada na Bacia do Prata) (Fernández, 2007; Higa, 2005; Siqueira, 2002).

Em relação à posse da terra, os meios de acesso sofreram modificações substanciais. No período colonial a sesmaria deteve o papel mais importante na formação da estrutura fundiária (Canavarros, 2004; Silva, 2008). Com a promulgação da Lei de Terras em 1850, estabeleceu-se que o seu acesso fosse regido por contrato de compra e venda. Com a mudança do regime imperial para o republicano (iniciado em 1889), implementa-se o sistema federativo e os estados passaram a ter controle das terras devolutas ${ }^{5}$ situadas em seus

4. Poaia é um arbusto cuja raiz é rica em emitina, utilizada na fabricação de diversos medicamentos.

5. Terras devolutas se referem às áreas públicas que nunca pertenceram a um particular, mesmo estando ocupadas por eles (RAVACHE, 2013). 
respectivos territórios. Entre 1892 e 1930, as terras públicas de Mato Grosso passaram para o domínio particular por meio de diferentes processos, como regularização das concessões de sesmarias, legitimação das posses, concessões gratuitas, venda e arrendamento (Moreno, 2007). Apesar destas importantes mudanças, a concentração fundiária permeou os diferentes períodos.

\section{POLÍTICAS PÚBLICAS DE OCUPAÇÃO EM MATO GROSSO}

Até meados do século Xx havia uma grande quantidade de terras, sobretudo nas áreas de cerrado (Planalto dos Alcantilados-Alto Araguaia, Planalto e Chapada dos Guimarães, Planalto e Chapada dos Parecis), que ainda não estavam sendo exploradas com fins econômicos. Este vasto território era tradicionalmente ocupado por diferentes povos indígenas, os quais se constituíam, na perspectiva do governo, em verdadeiras barreiras para o avanço da fronteira agrícola. Por isso, estas áreas passaram a ser alvo dos programas de colonização a partir do final dos anos trinta.

O primeiro programa foi «Marcha para Oeste», lançado em 1937 por Getúlio Vargas, que tinha como objetivo unificar as fronteiras econômicas e políticas, garantindo a integridade nacional, que se encontrava fragmentada pela existência de grandes vazios demográficos (Ricardo, 1970). Para tanto, em 1943 foram criadas duas estratégias inter-relacionadas: a) a expedição Roncador-Xingu, que procurava reconhecer uma vasta área no Norte de Mato Grosso, bem como definir locais estratégicos para formação de cidades, pistas de pouso e estradas; b) a Fundação Brasil Central, cuja finalidade era implantar núcleos populacionais, criando infraestrutura para a chegada dos emigrantes (Villas Bôas \& Villas Bôas, 2012; Ricardo, 1970). Estes programas nacionais promoveram um processo de expropriação das terras indígenas para torná-las disponíveis às frentes de expansão. Segundo Fernández (2007: 157-159),

$a$ «disponibilidade» dos chamados "grandes estoques» de terras, encravados nos denominados «vazios» populacionais, decorre de um longo processo social de construção de novos territórios, processo esse pautado na desarticulação e desestruturação de territórios tradicionais de caça, pesca, roças, moradia, rituais, conflitos e lazer dos povos indígenas [...]. Portanto, a expansão da fronteira ocorreu através do despovoamento e da desterritorialização de modos de vida tradicionais [...]. Assim se fabricou o "grande estoque de terras» e os "vazios demográficos», que foram os motes dos programas voltados a realizar a unificação da «fronteira política» com a «fronteira econômica». 
Em 1949, foi aprovado o Primeiro Código de Terras de Mato Grosso, o qual foi «aprimorado» em 1951, proporcionando maior liberdade na legislação referente à venda de terras devolutas, por meio da concessão a empresas particulares. Para estimular as vendas, foi definido um preço para a comercialização das terras, que oscilava de sete a dez cruzeiros (enquanto que em Goiás, por exemplo, os preços médios variavam de 44 a 279 cruzeiros). Os baixos preços e as facilidades legais de requerimento refletiram-se no crescimento da venda das terras devolutas. De 1951 a 1955, o Órgão de Terras do Estado de Mato Grosso recebeu 20.700 requerimentos de compra e regularização de terras, o que resultou em 10.300 concessões e 7.300 emissões de títulos provisórios, totalizando 21,9 milhões de hectares; ainda foram emitidos 3.100 títulos definitivos, distribuídos em 11 milhões de hectares (Fernández, 2007; Moreno, 2007). Portanto, 36,4\% da área de Mato Grosso foi vendida em cinco anos para empresas particulares (incluindo neste cálculo tanto os títulos provisórios quanto os definitivos).

No regime militar (1964 a 1985), ocorreu uma nova fase de ocupação do território mato-grossense por meio da criação de diversos programas, que visavam o avanço dos projetos agropecuários. Por um lado, esta iniciativa tinha como foco amenizar os problemas agrícolas, agrários e demográficos em processo no Nordeste e no Sul do país, onde estavam presentes os conflitos fundiários, a ausência de políticas para os camponeses e as precárias relações de trabalho. Por outro lado, havia uma preocupação com a segurança nacional, visto que se tratava de uma vasta região de fronteira desabitada (Tavares dos Santos, 1993; Fernández, 2007).

Nos parágrafos a seguir são apresentados os principais planos e programas executados durante o regime militar em Mato Grosso, destacando as áreas de ação e os instrumentos de intervenção ${ }^{6}$.

O primeiro destes programas foi o Plano de Valorização Econômica da Amazônia $(\mathrm{PVEA})^{7}$, institucionalizado em 1966, cujo objetivo era promover o desenvolvimento autossustentado da economia e o bem-estar social da Região Amazônica. O PVEA estruturava-se em três áreas de ação: a) políticas de incentivos fiscais; b) disponibilização de terras; c) construção de infraestrutura (sobretudo estradas). Com essas medidas, buscavase atrair o interesse de grandes empresas das regiões Sudeste e Sul para investir na Ama-

6. Para maior aprofundamento no tema, consultar TAVARES dos SANTos (1993), Moreno (2005, 2007), FERNÁNDEZ (2007), Rocha (2010) e RAVACHE (2013)

7. O estado de Mato Grosso faz parte da Amazônia brasileira por meio da Lei 1.806 de 6 de janeiro de 1953. Com esse dispositivo, a Amazônia Brasileira passou a ser chamada de Amazônia Legal, constituída por conceito político e não necessariamente por imperativos geográficos. 
zônia ${ }^{8}$. É pertinente atentar que os grandes estabelecimentos foram os principais beneficiados. De 1966 a 1976, a Superintendência do Desenvolvimento da Amazônia (criada para coordenar e executar o Plano) financiou 194 projetos, sendo $0,4 \%$ para os imóveis com até 5.000 hectares, $5,4 \%$ em imóveis com até 10.000 hectares e $94,1 \%$ naqueles acima de 10.000 hectares (predominando aqueles com área entre 20.000 e 50.000 hectares) (Fernández, 2007).

Em 1970, foi criado o Plano de Integração Nacional, que tinha como foco promover uma maior integração da economia. Para tanto, a prioridade era construir rodovias, como a BR-163, que liga Cuiabá a Santarém, e a Transamazônica, reservando uma faixa de 10 quilômetros de cada lado das rodovias para colonização e reforma agrária, a fim de fomentar a expansão da fronteira agrícola. No ano seguinte, essa extensão seria ampliada para cem quilômetros, garantindo à União um controle sobre mais de $60 \%$ do território mato-grossense (Moreno, 2007; Rocha, 2010).

Em 1971, o governo federal criou o Programa de Redistribuição de Terras e de Estímulo à Agroindústria do Norte e Nordeste. Com

recurso inicial de quatro bilhões de cruzeiros, valor duas vezes maior do que o destinado para a abertura da BR-163 e Transamazônica, o programa tinha por objetivo incentivar a implantação dos projetos de colonização, bem como assegurar recursos para a abertura de áreas e aquisição de insumos (Fernández, 2007: 163).

Conforme Rocha (2010), a previsão era vender estas terras para pequenos e médios produtores da região e ainda financiar parte da transação mediante a concessão de empréstimos fundiários, mas segundo Martins (1984), os estabelecimentos com mais de mil hectares receberam $71 \%$ das terras de 1970 a 1975 .

Também em 1971 foi criado o Programa de Desenvolvimento do Centro-Oeste que, grosso modo, visava investimentos em infraestrutura de transporte (basicamente construção de malha rodoviária) no intuito de proporcionar o escoamento da produção até os principais polos de comercialização, consumo, industrialização e exportação. O programa estava em consonância com os objetivos traçados no Plano de Integração Nacional ao dotar a região de infraestrutura básica na intenção de direcionar fluxos migratórios provindos

8. Para isso, foi criada a Lei 5.174 em outubro de 1966, que dava o direito de uma empresa investir até $50 \%$ do seu imposto de renda em projetos agrícolas, pecuários e industriais na Amazônia. Ademais, quando instaladas, gozavam de isenção plena do imposto de renda e de facilidades no acesso a terra (FERNÁNDEZ, 2007). 
de regiões onde se iniciavam os conflitos por terra ou de áreas densamente povoadas (Rocha, 2010).

Ainda em 1971, foram criados os Corredores de Exportação Articulados, que tinham como objetivos: diversificar e aumentar as exportações de produtos agropecuários; modernizar a economia por meio da implantação de infraestrutura de produção e comercialização dos produtos agrícolas; aumentar o consumo interno. Em termos práticos, a principal meta era viabilizar o acesso de Mato Grosso aos quatro principais portos de escoamento da produção brasileira: Porto de Tubarão, Porto de Santos, Porto de Paranaguá e Porto do Rio Grande (Moreno, 2005; Silva, 2011).

Em 1974, o Programa de Polos Agropecuários e Agrominerais da Amazônia recebeu recursos para promover o aproveitamento integrado das potencialidades agropecuárias, agroindustriais e florestais de 15 regiões selecionadas, sendo que três estavam localizadas em Mato Grosso: Xingu-Araguaia, Juruena e Aripuanã. Estes polos receberam obras de infraestrutura, tornando possível a implantação de vários projetos de colonização de pequenos e médios produtores na região (Tavares dos Santos, 1993; Rocha, 2010).

O Programa de Desenvolvimento dos Cerrados vigorou de 1975 a 1980 e tinha como objetivo promover o rápido desenvolvimento e a modernização das atividades agrícolas no Centro-Oeste brasileiro (Queiroz, 2004). Entre 1977 e 1979, cerca de 3,7 milhões de hectares foram beneficiados, com investimentos diretos em rodovias, armazenagem, crédito rural, rede elétrica, incentivos fiscais, recursos para pesquisa agropecuária e assistência técnica. Segundo Warnken (1999), o programa foi direcionado principalmente às grandes e médias propriedades rurais, visto que apenas $10 \%$ das linhas de crédito destinaramse aos estabelecimentos com área inferior a 200 hectares. Este instrumento viabilizou a incorporação de quase 2,5 milhões de hectares à agricultura intensiva e à pecuária no cerrado brasileiro, sendo a soja um dos cultivos mais beneficiados.

O Programa de Cooperação Nipo-Brasileiro para o Desenvolvimento do Cerrado foi criado em 1979 e visava fortalecer a ocupação do cerrado com bases técnicas e gerenciais modernas, por meio do acordo firmado entre o Brasil e o Japão para a produção de soja no cerrado, visto o interesse do país asiático na importação da oleaginosa. Um de seus objetivos foi o assentamento de agricultores do Sul e Sudeste do país que tivessem experiência no uso de tecnologias e que possuíssem vínculos com cooperativas agrícolas ou associações de produtores rurais (Inocêncio \& Calaça, 2009). O programa foi implementado em três fases, cobrindo os estados de Minas Gerais, Mato Grosso do Sul, Mato Grosso, Goiás, Bahia, Tocantins e Maranhão, onde foram realizados 21 projetos com 758 
assentados, incorporando 353.748 hectares de cerrados ao processo produtivo (Warnken, 1999; Rocha, 2010).

Por fim, cabe considerar o Programa Integrado de Desenvolvimento do Noroeste do Brasil, criado em 1981 com $66 \%$ dos recursos oriundos do governo brasileiro e $34 \%$ do Banco Mundial. Esta política abrangeu a área de influência da rodovia BR-364, entre Cuiabá (MT) e Porto Velho (RO), e seu principal objetivo era o asfaltamento dos 1.400 $\mathrm{km}$ da rodovia (Souza \& Pessoa, 2009). Segundo Moreno (2005), o programa contribuiu para acelerar a apropriação da terra por grupos empresariais, bem como o aumento do fluxo migratório de colonos que se dirigiam aos projetos de colonização. Com isso, houve uma redução dos territórios indígenas (ainda que algumas áreas tenham sido demarcadas) e o aumento da degradação ambiental (queimadas, desmatamento, mau uso do solo, etc.).

Como pode ser visto, as diferentes políticas públicas descritas acima promoveram, em distintas regiões de Mato Grosso, incentivos fiscais, concessão de terras, construção de infraestrutura, modernização da agricultura, ocupação do território, etc. Apesar de os grandes produtores serem os principais beneficiados por estes programas, também foram criados programas de colonização em regime de pequenas propriedades. Em relação aos programas de colonização, existem basicamente duas modalidades: oficial e particular.

$\mathrm{Na}$ Colonização Oficial cabe ao poder público, neste caso o INCRA (Instituto Nacional de Colonização e Reforma Agrária), planejar, coordenar e executar as atividades necessárias para implantação do projeto. No periodo de 1970 a 1980 foram criados no estado de Mato Grosso nove Projetos de Assentamento Rápido, em uma área de 270 mil hectares, para atender 4.524 familias. No início dos anos de 1970 foram criados quatro Projetos de Ação Conjunta (PAC) em 510 mil hectares, com capacidade para assentar 7.579 famílias. Nesta modalidade, o INCRA era responsável pela implantação da infraestrutura e titulação dos lotes e a cooperativa assumia a administração e manutenção dos projetos.

Na Colonização Particular, modalidade de assentamento criada com a finalidade de "complementar e ampliar a ação do Poder Público na política de acesso à propriedade rural», a empresa colonizadora tinha a responsabilidade de planejar e executar todas as etapas do projeto de colonização. Ao longo dos anos de 1970 e 1980 foram criados 88 projetos de colonização particular ${ }^{9}$, abrangendo uma área de 3,2

9. FERNÁNDEZ (2007) aponta para a presença de grande número de empresas de colonização privada em Mato Grosso, que estava vinculada à facilidade de aquisição de terras e às vantagens finan- 
milhões de hectares, com capacidade para assentar 20 mil familias em lotes rurais e 49 mil em lotes urbanos. Estas áreas eram destinadas, prioritariamente, para colonos da região Sul (Fernández, 2009: 10-11).

Portanto, foram criados mais de cem projetos de colonização (entre particulares e oficiais) de 1970 a 1980, beneficiando diretamente 81.000 famílias (entre lotes rurais e urbanos) em uma superfície de aproximadamente 4 milhões de hectares (equivalente ao território da Holanda). A Figura 2 confirma que a implementação dos projetos de colonização ocorreu majoritariamente na faixa de cem quilômetros ao longo das estradas federais, sobretudo na região do Médio Norte Mato-grossense, que compreende o Planalto dos Parecis, até então pouco explorada por processos anteriores de ocupação.

\section{FIGURA 2}

\section{Localização dos projetos de colonização criados em Mato Grosso entre 1970 e 1980}



Fonte: Piaia (2003).

ceiras concedidas pelo Estado. A colonização privada se transformou em uma lucrativa atividade econômica: compravam-se terras a preços baixos (ou adquiria-se direto da União ou por meio de processos irregulares de grilagem) e as revendiam aos colonos a preços superiores. 


\section{TRANSFORMAÇÕES AGRÁRIAS EM MATO GROSSO DE 1940 A 2006}

A constituição e a implementação de políticas públicas nas regiões da floresta amazônica e do cerrado afetaram diretamente a estrutura agrária mato-grossense. Em 1940, período que antecede esses programas, no meio rural haviam poucos estabelecimentos agropecuários (4.326), que se concentravam principalmente nos municípios pantaneiros (Poconé, Santo Antônio do Leverger e Nossa Senhora do Livramento) e naqueles em que havia núcleos de garimpo (Cuiabá, Poxoréo e Guiratinga). Conforme o Censo Agrícola de 1940, a área total dos estabelecimentos era de 4,1 milhões de hectares, atingindo apenas $4,6 \%$ de todo território do estado. Apesar do pequeno número de pessoas ocupadas (32.000), a média de ocupações por estabelecimento era alta (mais de 7 pessoas por unidade). Nesse período, era soberana a presença de proprietários ( $88 \%$ dos informantes), com poucos ocupantes ( $7 \%)$, arrendatários (3\%) e administradores (2\%).

Grande parte das terras em Mato Grosso destinava-se às pastagens (60\%), visto que a pecuária era a atividade predominante (principalmente bovinos, com mais de 100.000 cabeças, além de suínos e aves, estes majoritariamente para autoconsumo). Dentro da agricultura destacava-se a cana de açúcar, que produziu 18.200 toneladas em 1940, transformadas em aguardente, rapadura e açúcar, sendo comercializadas no mercado doméstico. Nesse ano também consta a presença de diferentes produtos -principalmente para subsistência das famílias, mas também para o mercado local- como arroz, feijão e milho, cultivados em mais de $85 \%$ dos estabelecimentos, além da plantação de mandioca, banana e laranja. A área com lavouras ocupava apenas 3\% da superfície total dos estabelecimentos e o restante era formado por matas e terras não utilizadas para fins agropecuários. É importante destacar que as atividades agrícolas eram realizadas com trabalho humano e animal, sem a presença de máquinas motorizadas - neste ano existia apenas um trator em todo o estado, que se localizava no município de Cuiabá.

Na década de 1950, ocorreu uma ampliação da área total dos estabelecimentos agropecuários, passando de 4,1 milhões para 7 milhões de hectares (aumento de 67,6\%), enquanto o número de unidades cresceu apenas $17 \%$, provocando um acréscimo na área média dos estabelecimentos em Mato Grosso, que chegou a quase 1.400 hectares. Em 1960, ocorreu um movimento inverso, pois a área total manteve-se praticamente estável e houve um crescimento no número de estabelecimentos, que ficou próximo aos 13.000, decaindo a área média para 600 hectares. O número de ocupações, após apresentar uma redução entre 1940 e 1950, dobrou de tamanho em 1960 (Quadro 1).

O aumento no número de estabelecimentos agropecuários não ocorreu de forma equitativa em todos os estratos. Ao contrário, o que houve foi uma ampliação das unidades 
menores, com área inferior a 100 hectares, que passaram de 2.000 para 8.000 de 1950 a 1960 (crescimento de 290\%), enquanto que os demais estratos tiveram um acréscimo muito mais modesto (36\%). Com esse resultado, o número de estabelecimentos com até 100 ha alcançou $62 \%$ do total em 1960, enquanto que em 1940 respondia por apenas $25 \%$. Apesar desse desempenho, continuaram a responder por uma parcela muito pequena da área total (2\%), o que indica que as transformações não foram suficientes para alterar a estrutura fundiária do estado neste período.

Outra mudança importante que se observou em 1960 foi na condição do produtor, com um crescimento no número de ocupantes (que passou de 7\% em 1940 para 28\%) em detrimento dos proprietários, que equivaliam a $88 \%$ dos informantes, mas foram perdendo peso e alcançaram $60 \%$ em 1960 (enquanto os arrendatários e administradores continuaram com percentuais inferiores a $6 \%$ ). Esse novo perfil dos produtores reflete, em alguma medida, o crescimento expressivo dos estabelecimentos com menos de 100 hectares, que tiveram sua base nos primeiros programas de colonização, cujo título de propriedade geralmente tardava em ser obtido e, por isso, eram classificados como ocupantes nos Censos Agropecuários.

Em termos da utilização das terras, as pastagens continuaram predominantes $(62 \%)$, principalmente aquelas naturais, seguidas pelas matas (28\%). A pecuária, localizada principalmente na região do Pantanal, manteve-se como principal atividade econômica do meio rural, com um grande crescimento de 1940 a 1960 (havia 111.000 cabeças e passaram a 1,6 milhão). A área de lavouras teve uma ampliação mais modesta, saindo de 59.100 para 96.800 hectares, cujo principal destino era o cultivo de arroz, cana de açúcar, milho, feijão e mandioca. Apesar disso, a organização da produção - pautada no uso de força de trabalho humana e animal, no desenvolvimento de plantios consorciados e em pequenas escalas, na utilização de sementes crioulas e de fertilizantes naturais presentes no próprio estabelecimento, etc.- e o destino final dos produtos -voltados à subsistência da família, mercado local e, esporadicamente, mercado regional- continuaram muito próximos daqueles evidenciados em 1940.

Em suma, o ano de 1960 torna perceptíveis os primeiros reflexos da «Marcha para o Oeste» e do Plano de Metas, adotado no governo do Presidente Juscelino Kubitschek (1955-1960), uma vez que a construção de núcleos populacionais e a criação de infraestrutura influenciaram no aumento do número de pequenos estabelecimentos agropecuários e na presença de informantes categorizados como ocupantes. Contudo, grande parte desta ampliação ocorreu em áreas já utilizadas anteriormente, visto que a superfície total dos estabelecimentos não apresentou um aumento expressivo (Quadro 1). 


\section{QUADRO 1}

Número de estabelecimentos agropecuários, área total (hectares)

e pessoas ocupadas em Mato Grosso (1940-2006)

\begin{tabular}{|c|c|c|c|c|c|c|}
\hline Ano & $\begin{array}{c}\text { Estabelecimentos } \\
\text { agroprecuários }\end{array}$ & $\begin{array}{c}\text { Área dos } \\
\text { estabelecimentos } \\
\text { agropecuários }\end{array}$ & $\begin{array}{l}\text { Área média dos } \\
\text { estabelecimentos } \\
\text { agropecuários }\end{array}$ & $\begin{array}{c}\text { Pessoas nos } \\
\text { estabelecimentos }\end{array}$ & $\begin{array}{l}\text { N. médio de } \\
\text { pessoas por } \\
\text { estabeleciment }\end{array}$ & $\begin{array}{c}\text { Área dos } \\
\text { estabelecimentos } \\
\text { o agropecuários sobre }\end{array}$ \\
\hline & (A) & (ha)(B) & (ha) (B/A) & (C) & (C/A) & área total do MT (\%) \\
\hline 1940 & 4.326 & 4.198 .498 & 971 & 32.340 & 7,5 & 4,6 \\
\hline 1950 & 5.068 & 7.037 .269 & 1.389 & 28.263 & 5,6 & 7,8 \\
\hline 1960 & 12.885 & 7.806 .303 & 606 & 55.392 & 4,3 & 8,6 \\
\hline 1970 & 46.090 & 17.274.746 & 375 & 373.039 & 8,1 & 19,1 \\
\hline 1975 & 56.118 & 21.949.147 & 391 & 263.179 & 4,7 & 24,3 \\
\hline 1980 & 63.383 & 34.554 .550 & 545 & 318.570 & 5,0 & 38,3 \\
\hline 1985 & 77.921 & 37.835 .653 & 486 & 359.221 & 4,6 & 41,9 \\
\hline 1996 & 78.763 & 49.849 .663 & 633 & 326.767 & 4,1 & 55,2 \\
\hline 2006 & 112.978 & 47.805 .514 & 423 & 358.336 & 3,2 & 52,9 \\
\hline
\end{tabular}

Fonte: elaboração própria, Censos Agropecuários, diferentes anos (IBGE, 2014).

O Censo Agropecuário de 1970 é um marco no estado de Mato Grosso, por permitir a visualização das primeiras transformações provocadas pelo Plano de Valorização Econômica da Amazônia e pelos programas de colonização oficial e particular. Os dados apontam para aumentos expressivos no número de estabelecimentos (que passou, em dez anos, de 12.800 a 46.000), na área total (crescimento de $120 \%$ ) e no número de pessoas ocupadas (que cresceu quase sete vezes). Um elemento importante foi a criação de estabelecimentos no centro-norte do estado, pois até então era muito pontual a presença de unidades de produção agropecuária naquela região.

A condição legal do responsável pelo estabelecimento também foi alterada de forma significativa de 1940 a 1970. Inicialmente era majoritária a presença de proprietário e nos anos seguintes houve um grande crescimento dos ocupantes $(30 \%)$ e arrendatários $(22 \%)$. Outro ponto que chama atenção diz respeito à estrutura fundiária, onde pela primeira vez se torna expressiva a presença de estabelecimentos com menos de 100 hectares de área total (responsáveis por $77 \%$ das unidades e $12 \%$ da área). Esses elementos vinculam-se à chegada dos primeiros agricultores intermediados pelos programas de colonização, que inicialmente eram instalados em pequenas propriedades na condição de ocupantes até obterem o título de propriedade da terra (Moreno, 2005, 2007).

No quadro da produção agropecuária começam haver mudanças importantes, tanto na ampliação da área plantada quanto no sistema de produção. $\mathrm{O}$ arroz consolidou-se 
como a principal atividade agrícola, com uma área cultivada de 152.000 hectares, o que correspondeu a um crescimento de $373 \%$ em relação à década anterior, seguido do milho, feijão, mandioca, algodão e cana. Contudo, o rebanho bovino continuava sendo a atividade de maior destaque, com 1,95 milhões de animais (crescimento de $22 \%$ em relação à década precedente). No que se refere às transformações no sistema de produção, Fernández (2007) argumenta que a agricultura deixou de ser uma atividade de áreas de mata para ocupar lugar no cerrado. Para o autor, esta mudança foi estimulada pelo processo de migração, que levou para o sul de Mato Grosso (formado pelos municípios de Rondonópolis, Itiquira, Jaciara, Poxoréu) famílias de vários estados brasileiros. Além disso,

o dominio de técnicas de mecanização e correção dos solos possibilitou a abertura dos cerrados para as lavouras mecanizadas, inicialmente o arroz, devido a sua maior resistência à acidez dos solos. Após um ou dois anos de cultivo a lavoura de arroz era substituída por pastagens, dando início à ampliação da área com pastagens cultivadas. Deste modo, a pecuária de regime extensivo em pastagens naturais vai sendo substituída pela pecuária extensiva em pastagens plantadas, saindo da região do pantanal para áreas de terras altas (Fernández, 2009: 54).

Conforme Graziano da Silva (2003), o número de tratores existente nos estabelecimentos agropecuários é um importante indicador do aumento do acesso a novas tecnologias no campo. Seguindo essa orientação, são evidentes as transformações no espaço rural mato-grossense de 1960 a 1970, visto que o número de tratores passou de 34 para 600. Além disso, nesse mesmo intervalo, foi crescente o uso de arado, tem início a utilização de fertilizantes e chegam no estado as primeiras colheitadeiras. É importante destacar que muitos agricultores, cuja região de origem já estava «adiantada» no processo de modernização da agricultura, ao migrarem para o Mato Grosso, levaram consigo alguns implementos agrícolas, maquinário e insumos (principalmente sementes).

Em 1985, foi possível visualizar os resultados, ainda que iniciais, dos programas de colonização e das diferentes políticas implementadas em Mato Grosso. Por um lado, alguns movimentos verificados em 1970 continuaram ganhando força, como o aumento no número de estabelecimentos agropecuários (principalmente no Centro-Norte do estado) e na área total, que passou a cobrir mais de $40 \%$ do território mato-grossense. Por outro lado, o número de ocupações acabou mantendo-se relativamente estável, ainda que com algumas variações entre os anos. Isso se refletiu na ampliação da área por pessoa ocupada, que passou de uma média de 46 hectares em 1970 para 105 hectares em 1985.

A categoria que mais cresceu de 1970 a 1985 foi a de proprietários, que passou de 19.800 para 48.800. Como já comentado, esse resultado deriva do crescente esforço do 
Estado, por meio do Instituto Nacional de Colonização e Reforma Agrária e do Instituto de Terras do Estado de Mato Grosso, em regularizar a situação fundiária, principalmente de produtores e/ou empresários do centro-sul do país, que migraram para a região estimulados pelo baixo preço da terra, pelos incentivos fiscais, pelos programas de colonização, etc. Conforme Moreno (2007: 159),

o INCRA arrecadava grandes extensões de terras devolutas, após a realização do procedimento discriminatória, e procedia à «licitação pública», dando preferência de compra ao empresário ocupante. Foi assim que diversos empresários do centrosul do país tornaram-se também grandes proprietários de terra em Mato Grosso. Inicialmente «ocupavam» terras ao longo de rodovias federais ou nas áreas consideradas indispensáveis à segurança e ao desenvolvimento nacional, depois adquiriam-nas a preços simbólicos, justificado pela ocupação pioneira e desbravamento das áreas de cerrados ou floresta para a implantação da empresa capitalista.

Esse esforço da política federal de regularização fundiária acabou legalizando muitas áreas ocupadas, inclusive aquelas resultantes de atos de grilagem (Moreno, 2005, 2007). Essa «transformação» de ocupantes em proprietários fez com que os primeiros fossem perdendo peso relativo ao longo dos anos (passaram de 30\% em 1970 para 4\% em 2006), enquanto os segundos cresceram significativamente no mesmo período (Figura 3).

Em termos de produção agropecuária, o ano de 1985 pode ser considerado como o momento de consolidação de um novo ciclo, que teve início em 1970. Este padrão produtivo ficou associado a: monocultura, escalas de produção, utilização de insumos mo-


dependência das grandes empresas do sistema agroindustrial (Kageyama et al., 1990; Graziano da Silva, 1998; Ploeg, 2006, 2008). Alguns cultivos para fins comerciais fortaleceram-se neste período, como foi o caso da soja, que alcançou 300.000 hectares em 1985, e da cana de açúcar, com 19.000 hectares no mesmo ano. O arroz, que era o cultivo com maior área cultivada em 1970 (446.000 hectares), passou a perder espaço (após atingir o pico de 866.000 hectares em 1980) diante das novas tecnologias de correção dos solos. Além disso, contribuiu para sua decadência a queda no preço (quando comparado com a soja, por exemplo), a falta de garantia de compra e o surgimento de novas doenças nas plantas, que aumentaram o custo de produção.

10. O número de tratores passou de 600 para 19.500 entre 1970 e 1985.

Historia Agraria, 72 • Agosto 2017 • pp. 167-194 


\section{FIGURA 3}

Número de estabelecimentos agropecuários segundo a condição do produtor em relação às terras em Mato Grosso (1940-2006)



Fonte: elaboração própria, Censos Agropecuários, diferentes anos (IBGE, 2014).

O Censo Agropecuário de 1995-1996 aponta transformações importantes na estrutura agrária mato-grossense (ainda que essas alterações possam ser reflexos das mudanças metodológicas no Censo ${ }^{11}$ ). O número de estabelecimentos agropecuários manteve-se estável de 1985 a 1996 e as ocupações tiveram uma queda de 9\%. A área total, por sua vez, cresceu mais de $30 \%$ e passou a cobrir $55 \%$ do território do estado. A área média por unidade ficou acima de 600 hectares, valor próximo daquele encontrado em 1960.

Outro elemento que ganha destaque é a consolidação dos proprietários, que atingem $87 \%$ dos informantes. É interessante perceber que a condição do produtor é praticamente idêntica àquela de 1940. Isso demonstra que, apesar das profundas transformações agrárias ocorridas em Mato Grosso ao longo de cinquenta anos, os proprietários voltaram a controlar a grande maioria dos estabelecimentos (o menor percentual foi em 1970 e 1975, em meio aos programas de colonização).

11. O Censo Agropecuário de 1995-1996 teve como período de referência 31/12/1995 a 31/07/1996 (ano agrícola), sendo 31/12/1995 para as informações sobre propriedade, área e pessoal ocupado e 31/07/1996 para informações sobre efetivos da pecuária, da lavoura permanente e da silvicultura. Para os Censos Agropecuários anteriores e para o de 2006, o período de referência foi o ano civil (01/01 a 31/12), sendo 31/12 para informações de séries de estoque. Deste modo, os dados de 19951996 não são estritamente comparáveis com os demais. 
No que se refere à utilização das terras, 1996 é o primeiro ano em que as pastagens plantadas (30,6\% da área total dos estabelecimentos) superaram as naturais $(12,4 \%)$. Esse resultado reflete a busca por maiores rendimentos por hectare, bem como a expansão da pecuária para áreas de cerrado e floresta amazônica. Inclusive o número de bovinos passou de 6,5 milhões para 14,4 milhões de cabeças de 1985 a 1996, o que representa um crescimento de $121 \%$, principalmente nas mesorregiões Norte e Nordeste Mato-grossense. A área de mata também teve um crescimento na sua superfície, que decorre do avanço dos estabelecimentos sobre áreas de floresta nativa e não do reflorestamento (que responde por apenas $0,1 \%$ do total). A área de lavoura cresceu 822.000 hectares, mas manteve os 7\% sobre a área total, mesmo percentual que havia alcançado em 1985 (Quadro 2). Os produtos com maior crescimento foram a soja, cana de açúcar e milho, enquanto arroz, feijão e mandioca tiveram queda na produção e na área cultivada (esse resultado pode estar relacionado com as mudanças metodológicas acima mencionadas).

\section{QUADRO 2}

Área total dos estabelecimentos por formas de utilização das terras em Mato Grosso (1940-2006) (\%)

\begin{tabular}{|c|c|c|c|c|c|c|c|c|c|}
\hline \multirow[t]{2}{*}{ Ano } & \multicolumn{2}{|c|}{ Lavouras } & \multicolumn{2}{|c|}{ Pastagens } & \multicolumn{2}{|c|}{ Matas } & \multirow{2}{*}{$\begin{array}{l}\text { Terras } \\
\text { inaprov. }\end{array}$} & \multirow{2}{*}{$\begin{array}{l}\text { Terras não } \\
\text { utilizadas }\end{array}$} & \multirow[t]{2}{*}{ Total } \\
\hline & Perm. & Temp. & Naturais & Artific. & Naturais & Reflor. & & & \\
\hline 1940 & 1,9 & 1,5 & \multicolumn{2}{|c|}{$60,1^{*}$} & \multicolumn{2}{|c|}{$20,8^{*}$} & 8,3 & 7,4 & 100 \\
\hline 1950 & 0,1 & 0,8 & 53,1 & 1,4 & 33,0 & 0,2 & 7,7 & 3,7 & 100 \\
\hline 1960 & 0,2 & 1,0 & 57,1 & 4,4 & 27,3 & 0,2 & 6,6 & 3,2 & 100 \\
\hline 1970 & 0,1 & 2,4 & 47,6 & 7,7 & 29,5 & 0,0 & 5,4 & 7,3 & 100 \\
\hline 1975 & 0,2 & 2,2 & 39,4 & 11,9 & 32,4 & 0,1 & 3,8 & 10,1 & 100 \\
\hline 1980 & 0,4 & 5,0 & 29,2 & 13,6 & 38,7 & 0,1 & 5,8 & 7,2 & 100 \\
\hline 1985 & 0,4 & 6,4 & 25,6 & 17,8 & 37,3 & 0,1 & 6,7 & 5,8 & 100 \\
\hline 1996 & 0,3 & 6,6 & 12,4 & 30,6 & 43,1 & 0,1 & 3,9 & 2,9 & 100 \\
\hline 2006 & 0,8 & 12,7 & 9,0 & 36,3 & 39,2 & 0,1 & 1,2 & 0,5 & 100 \\
\hline
\end{tabular}

${ }^{\star}$ Os dados de pastagens e matas foram apresentados de forma agregada em 1940.

Fonte: elaboração própria, Censos Agropecuários, diferentes anos (IBGE, 2014).

Os dados do último Censo Agropecuário (2006) indicam um aumento importante no número de estabelecimentos (43\%), com redução da área total (mas, como já ponderado, a comparabilidade entre os dados de 1996 e 2006 precisa ser sempre questionada). A ampliação no número de unidades ocorreu, sobretudo, entre os proprietários (que passaram de 68.200 para 88.700) e os assentados sem titulação definitiva (foi a primeira vez que se contabilizou tal dado, com o registro de 16.900 informantes), enquanto os ocupantes e parceiros caíram quase pela metade -os arrendatários mantiveram-se estáveis. A estrutura fundiária também apresentou algumas mudanças, como o aumento das unidades 
com menos de 100 hectares, tanto no número de estabelecimentos (passou de 38.500 para 74.300) como na área total (foi de 1,6 para 2,6 milhões de hectares). Essas alterações foram provocadas, principalmente, pela criação de assentamentos da reforma agrária, que passaram de 57 unidades em 1995 para 477 em 2006 (Dataluta, 2012).

Chama atenção o crescimento das áreas de lavouras, sobretudo temporárias, e a redução das terras improdutivas e inaproveitáveis, além da manutenção do forte peso das pastagens plantadas e da mata nativa. Em termos de produtos, ocorreu um aumento muito grande na produção de soja, algodão, milho e cana-de-açúcar. Por outro lado, os produtos básicos da alimentação cotidiana (arroz, feijão e mandioca) apresentaram uma redução ou manutenção da área cultivada. Esses elementos confirmam o trajeto recente da agricultura mato-grossense, que se voltou majoritariamente aos produtos destinados à exportação. O mesmo ocorreu com a pecuária (bovinos, suínos e aves), que teve um aumento muito expressivo no número de cabeças, e que segue, em grande medida, para o mercado externo depois de processada.

Vale destacar que os produtos para exportação foram beneficiados por uma política econômica favorável, que manteve o câmbio desvalorizado, diferentemente do que ocorria em 1995-1996, quando a moeda brasileira estava equiparada ao dólar. Além disso, é inegável a influência da demanda externa (principalmente asiática), o preço favorável em determinados períodos, os profundos avanços tecnológicos (tanto em nível genético como nas máquinas agrícolas e nos defensivos), crescimento da oferta de crédito rural (o SNCR ampliou seu volume de recursos em mais de três vezes de 1996 a 2005), etc. (Delgado, 2012; Wesz Jr., 2014).

Como já foi destacado anteriormente (Quadro 1), os estabelecimentos cobriam menos de 5\% do território mato-grossense em 1940. Ao longo dos anos houve uma enorme incorporação de novas terras à atividade agropecuária e, no último Censo Agropecuário, a superfície controlada por produtores rurais chegava a metade da área de Mato Grosso -o restante pertence às cidades, reservas indígenas, áreas de conservação, estabelecimentos sem atividade agropecuária ${ }^{12}$, etc. A Figura 4 permite acompanhar este movimento em nível municipal, evidenciando que até 1980 a maior proporção territorial utilizada para atividades agrícolas e pecuárias ainda estava nas localidades meridionais do estado. Esta situação diferencou-se em 2006, quando vários municípios do centro-norte passaram a

12. Os censos analisados consideram como estabelecimento agropecuário todo terreno onde há exploração agropecuária, ou seja, cultivo do solo com culturas permanentes e temporárias, inclusive hortaliças e flores; a criação, recriação ou engorda de animais de grande e médio porte; a criação de pequenos animais; a silvicultura ou o reflorestamento; e a extração de produtos vegetais (IBGE, 2014: 1). Portanto, estabelecimentos sem o exercício de atividade agropecuária não são considerados no levantamento de dados. 
deter mais de $60 \%$ da sua área controlada por estabelecimentos agropecuários -ficando abaixo de $30 \%$ sobretudo naquelas localidades que detinham parte importante da sua superfície com reservas indígenas e áreas de conservação.

FIGURA 4

Percentual da área dos estabelecimentos agropecuários sobre a área total dos municípios


1980


Fonte: elaboração própria, Ipeadata (2014) e IBGE (2014).

Ao analisar a estrutura fundiária de 1940 a 2006, pode-se dizer que a concentração na posse da terra continua presente, na qual os estabelecimentos acima de dois mil hectares continuam respondendo por mais de dois terços da área total (Quadro 3). Entretanto, houve uma redução desta concentração de 1975 em diante, visto que nesse ano $80 \%$ das terras estavam nos estabelecimentos com mais de dois mil hectares, caindo para $67 \% \mathrm{em}$ 
2006. Entretanto, se focar exclusivamente nos dados de área em 1940 e 2006, é possível identificar semelhança nos percentuais. O Quadro 3 ainda permite afirmar que as unidades com menos de 50 hectares representam 44,7\% dos estabelecimentos, mas controlam apenas $2,3 \%$ da área total. Por outro lado, menos de $5 \%$ dos produtores detém dois terços da superfície total em 2006. Segundo o IBGE (2014), Mato Grosso é o segundo estado brasileiro com maior concentração na distribuição da terra (com índice de Gini de 0,865 em 2006), perdendo apenas para Alagoas, que alcança 0,871.

\section{QUADRO 3}

Número e área dos estabelecimentos agropecuários por estratos

de área total em Mato Grosso (1940-2006) (\%)

\begin{tabular}{|c|c|c|c|c|c|c|c|c|c|}
\hline \multirow[t]{2}{*}{ Estratos de área } & \multicolumn{9}{|c|}{ Número de estabelecimentos } \\
\hline & 1940 & 1950 & 1960 & 1970 & 1975 & 1980 & 1985 & 1996 & 2006 \\
\hline$<10$ ha & 7,6 & 10,4 & 24,4 & 45,1 & 47,6 & 36,4 & 30,3 & 9,2 & 11,2 \\
\hline$>10$ ha $<50$ ha & 9,0 & 17,0 & 28,8 & 25,6 & 23,2 & 22,4 & 26,5 & 29,6 & 33,5 \\
\hline$>50$ ha $<100$ ha & 8,3 & 9,1 & 8,4 & 6,4 & 7,1 & 9,6 & 11,2 & 17,8 & 21,2 \\
\hline$>100$ ha $<500$ ha & 47,2 & 19,8 & 18,5 & 10,9 & 10,3 & 17,7 & 18,3 & 25,1 & 19,0 \\
\hline$>500 \mathrm{ha}<2.000 \mathrm{ha}$ & 19,3 & 32,4 & 12,3 & 5,0 & 4,2 & 6,7 & 6,6 & 11,1 & 7,9 \\
\hline$>2.000 \mathrm{ha}$ & 7,4 & 10,6 & 6,0 & 2,9 & 3,0 & 4,6 & 4,3 & 6,4 & 4,3 \\
\hline \multirow[t]{3}{*}{ Total } & 100 & 100 & 100 & 100 & 100 & 100 & 100 & 100 & 100 \\
\hline & \multicolumn{9}{|c|}{ Área dos estabelecimentos } \\
\hline & 1940 & 1950 & 1960 & 1970 & 1975 & 1980 & 1985 & 1996 & 2006 \\
\hline$<10$ ha & 0,0 & 0,0 & 0,2 & 0,5 & 0,5 & 0,3 & 0,3 & 0,1 & 0,1 \\
\hline$>10$ ha $<50$ ha & 0,3 & 0,3 & 1,1 & 1,4 & 1,4 & 1,1 & 1,4 & 1,2 & 2,2 \\
\hline$>50$ ha $<100$ ha & 0,6 & 0,5 & 0,9 & 10,5 & 1,3 & 1,2 & 1,6 & 2,0 & 3,2 \\
\hline$>100$ ha $<500$ ha & 10,9 & 3,8 & 7,1 & 5,5 & 5,9 & 6,9 & 7,8 & 8,3 & 9,5 \\
\hline$>500 \mathrm{ha}<2.000 \mathrm{ha}$ & 20,9 & 16,4 & 18,6 & 11,2 & 10,8 & 11,6 & 13,4 & 16,1 & 18,5 \\
\hline$>2.000 \mathrm{ha}$ & 67,3 & 79,0 & 72,1 & 70,8 & 80,1 & 79,0 & 75,6 & 72,4 & 66,5 \\
\hline Total & 100 & 100 & 100 & 100 & 100 & 100 & 100 & 100 & 100 \\
\hline
\end{tabular}

Fonte: elaboração própria, Censos Agropecuários, diferentes anos (IBGE, 2014).

Ao descer a escala de análise para o nível municipal (Figura 5), percebe-se que a concentração na posse da terra diferencia-se entre as localidades. Desde 1940 até 2006 existem fortes variações na área média dos estabelecimentos agropecuários, sendo concomitante a presença de municípios com média abaixo de 500 hectares até aquelas com mais de 1.000 hectares. Nos quatro anos destacados existem municípios com média superior a três mil hectares, como Cáceres, Diamantino e Rosário Oeste em 1940; Nortelândia em 1960; Diamantino, Luciara e Santa Terezinha em 1980; Cocalinho, Santo Antônio do Leste e Sapezal em 2006. Vale destacar que estes últimos municípios citados possuíam 
as três maiores médias nacionais, liderado por Sapezal, que contava com 5.303 hectares de área média dos estabelecimentos agropecuários em 2006, enquanto a média brasileira era de 64,5 hectares (IBGE, 2014).

\section{FIGURA 5}

\section{Área média dos estabelecimentos agropecuários por município em Mato Grosso}


250

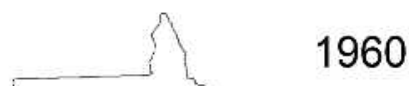

H11111

ficos, garantir a integridade nacional, unificar as fronteiras econômicas e políticas, promover o avanço de projetos agropecuários, reduzir conflitos agrários no Sul e Nordeste do Brasil, etc.) estas políticas acabaram transformando intensamente o estado, restando pouco das características presentes em 1940.

Apesar do forte aumento no número de estabelecimentos agropecuários, ampliação da superfície total das explorações rurais, crescimento das áreas de lavouras e pastagens artificiais, mudanças nos principais cultivos agrícolas e introdução de um novo padrão de produção, uma característica mantém-se no estado: fortíssima concentração na posse da terra. Inclusive algumas políticas públicas foram fundamentais para esse resultado ao beneficiar, de diferentes formas, os grandes proprietários - os programas de colonização de pequenos produtores e os assentamentos da reforma agrária criados em Mato Grosso foram insuficientes para provocar uma alteração substantiva na posse da terra.

Vale destacar que a presença de grandes estabelecimentos já existia antes de 1940 (originou-se no período colonial e permaneceu na independência e nas primeiras décadas da República), fortaleceu-se com as formas de distribuição e regularização implementado nos anos 1950 pelo Primeiro Código de Terras de Mato Grosso e foram estimuladas por meio de diferentes programas levados a cabo durante a ditadura militar. No período atual, esse segmento beneficiou-se com o aumento do preço das commodities, demanda por alimentos aquecida, avanço tecnológico, renegociação das dívidas dos produtores, crescimento dos recursos disponibilizados pelo crédito rural público, fortalecimento das entidades de representação do setor, legislação desatualizada, etc. É importante destacar que parte deste "contexto favorável» deve-se à presença e à atuação da Banca Ruralista ${ }^{13}$, que se tornou o maior grupo de interesse do parlamento brasileiro (Barcelos \& Berriel, 2009: $14)$.

Em suma, este estudo procurou elucidar alguns processos em curso em uma região de fundamental importância para a economia agropecuária do Brasil, destacando mudanças e continuidades na realidade agrária. Mais do que ratificar o "potencial agrícola» presente em Mato Grosso, tão forte nos discursos das lideranças do setor ou em algumas interpretações acadêmicas ou de gestores públicos, buscou-se apresentar alguns movimentos que perpassam o espaço rural nas últimas décadas, cuja compreensão é central para o entendimento das dinâmicas atualmente vigentes no estado.

13. Para aprofundar o tema da Banca Ruralista no Brasil, ver CosTA (2012) e BRUNO et al. (2009). 


\section{AGRADECIMENTOS}

Este artigo é resultado parcial da minha tese de doutorado (Wesz Jr., 2014) e gostaria de agradecer à orientação do prof. Dr. Sergio Pereira Leite e à bolsa de estudos do CNPq (Conselho Nacional de Desenvolvimento Científico e Tecnológico) e da Faperj (Fundação de Amparo à Pesquisa do Estado do Rio de Janeiro). Também agradeço à Beatriz Heredia, Leonilde Medeiros, Moacir Palmeira e Sergio Leite, coordenadores da pesquisa «Sociedade e economia do agronegócio: um estudo exploratório", e à Rosângela Pezza Cintrão, que possibilitam uma aproximação com o tema cartográfico e permitiram o acesso às bases municipais de diferentes anos. Por fim, agradeço aos avaliadores anônimos da revista Historia Agraria, que contribuíram na qualificação do trabalho.

\section{REFERÊNCIAS}

BARCELOS, E. A. S. \& BERRIEL, M. C. (2009). Práticas institucionais e grupos de interesse: A geograficidade da Bancada Ruralista e as estratégias hegemônicas no parlamento brasileiro. In XIX Encontro Nacional de Geografia Agrária. São Paulo.

BERNARDES, J. A. (2006). Circuitos espaciais da produção na fronteira agrícola moderna: BR-163 mato-grossense. In J. A. Bernardes \& O. DE L. Freire Filho (Eds.), Geografia da soja BR-163: Fronteiras em mutação. Rio de Janeiro: Arquimedes.

BRUNO, R. ET AL. (2009). Um Brasil ambivalente: Agronegócio, ruralismo e relações de poder. Rio de Janeiro: Mauad X/Edur-UFRRJ.

Canavarros, O. (2004). O poder metropolitano em Cuiabá (1727-1752). Cuiabá: EDUFMT.

Costa, S. H. G. (2012). A questão agrária no Brasil e a bancada ruralista no congresso nacional. Dissertação de mestrado em Geografia Humana. São Paulo: Universidade de São Paulo.

Dataluta-Banco de Dados da luta Pela Terra (2012). Mato Grosso: Relatório 2011. Cuiabá: NERA.

Delgado, G. C. (2012). Do capital financeiro na agricultura à economia do agronegócio: Mudanças cíclicas em meio século (1965-2012). Porto Alegre: Universidade Federal do Rio Grande do Sul.

Fernández, A. J. C. (2007). Do Cerrado à Amazônia: As estruturas sociais da economia da soja em Mato Grosso. Tese de doutorado em Desenvolvimento Rural. Porto Alegre: Universidade Federal do Rio Grande do Sul.

FERNÁNDEZ, A. J. C. (2009). Sociedade e economia do agronegócio: Estudo exploratório do estado de Mato Grosso. Relatório de pesquisa. Cuiabá. 
Graziano da Silva, J. (1998). A nova dinâmica da agricultura brasileira. $2^{\mathrm{a}}$ ed. Campinas: Universidade Estadual de Campinas.

Graziano DA Silva, J. (2003). Tecnologia e agricultura familiar. $2^{\mathrm{a}}$ ed. Porto Alegre: Universidade Federal do Rio Grande do Sul.

Higa, T. C. C. S. (2005). Processo de ocupação e formação territorial. In T. C. C. S. HigA \& G. Moreno (Eds.), Geografia de Mato Grosso: Território, sociedade, ambiente (pp. 18-33). Cuiabá: Entrelinhas.

Instituto Brasileiro de Geografia e Estatística (IBGE) (2014). Banco de dados agregados. http://www.sidra.ibge.gov.br [Acesso em: 12/01/2015].

InocÊNCIO, M. E. \& CALAÇA, M. (2009). Cerrado: Fronteira da produção agrícola capitalista do século XX. XIX Encontro Nacional de Geografia Agrária. São Paulo.

IPEADATA (2014). Estatísticas. http://www.ipeadata.gov.br [Acesso em: 15/09/2015].

KAGEYAMA, A. ET AL. (1990). O novo padrão agrícola brasileiro: Do complexo rural aos complexos agroindustriais. In G. C. Delgado (Ed.), Agricultura e políticas públicas (pp. 113-223). Brasília: Instituto de Pesquisa Economica Aplicada.

Ministério da Agricultura, Pecuária e Abastecimento (MAPA) (2014). AgroStat. agrostat.agricultura.gov.br [Acesso em: 02/06/2015].

Martins, J. DE S. (1984). A militarização da questão agrária no Brasil. Petrópolis: Vozes.

MARTINS, J. DE S. (1996). O tempo da fronteira: Retorno à controvérsia sobre o tempo histórico da frente de expansão e da frente pioneira. Tempo social, 8 (1), 25-70. http://dx.doi.org/10.1590/ts.v8i1.86141

Moreno, G. (2005). Políticas e estratégia de ocupação. In G. Moreno \& T. C. S. HigA (Eds.), Geografia de Mato Grosso:Território, sociedade, ambiente (pp. 34-51). Cuiabá: Entrelinhas.

Moreno, G. (2007). Terra e poder em Mato Grosso: Política e mecanismos de burla, 18921992. Cuiabá: Entrelinhas/EDUFMT.

PiaIA, I. I. (2003). Geografia de Mato Grosso. Cuiabá: EdUNIC.

Ploeg, J. D. vAN DER (2006). O modo de produção camponês revisitado. In S. SCHNEIDER (Ed.), A diversidade da agricultura familiar (pp.13-54). Porto Alegre: Universidade Federal do Rio Grande do Sul.

Ploeg, J. D. van DER (2008). Camponeses e impérios alimentares: Lutas por autonomia e sustentabilidade na era da globalização. Porto Alegre: Universidade Federal do Rio Grande do Sul.

QUEIROZ, F. A. (2004). Impactos do comércio internacional de soja sobre a biodiversidade do Cerrado. II Encontro da Associação Nacional de Pós-Graduação e Pesquisa em Ambiente e Sociedade. São Paulo. 
RaVACHe, R. L. (2013). Migração e modernização em cidades médias da Amazônia legal: Área de abrangência da BR 163. Tese de doutorado em Geografia Humana. São Paulo: Universidade de São Paulo.

Ricardo, C. (1970). A marcha para oeste. São Paulo: Universidade de São Paulo.

Rocha, B. N. (2010). "A trama do drama»: A trama das fronteiras e o drama dos migrantes nas configurações do desenvolvimento de Lucas do Rio Verde-MT. Tese de doutorado em Ciências Sociais em Desenvolvimento, Agricultora e Sociedade. Rio de Janeiro: Universidade Federal Rural do Rio de Janeiro.

SILVA,V. (2008). Administração das terras: A concessão de sesmarias na capitania de Mato Grosso (1748-1823). Dissertação de mestrado em História. Cuiabá: Universidade Federal de Mato Grosso.

SiLVA, F.V. (2011). O processo de expansão da fronteira agrícola moderna em Mato Grosso e a formação dos circuitos espaciais e da produção de fertilizantes. Dissertação de mestrado em Geografia. Cuiabá: Universidade Federal de Mato Grosso.

Siqueira, E. M. (2002). História de Mato Grosso: Da ancestralidade aos dias atuais. Cuiabá: Entrelinhas.

SouZA, M. M. O. \& PESsoA, V. L. S. (2009). A contra-reforma agrária em Rondônia: Colonização agrícola, expropriação e violência. V Encontro de Grupos de Pesquisa Agricultura, Desenvolvimento Regional e Transformações Socioespaciais. Santa Maria.

Tavares dos Santos, J.V. (1993). Matuchos. Exclusão e Luta: Do sul para a Amazônia. Petrópolis: Vozes.

VIllas BôAs, O. \& VIllas BôAs, C. (2012). A marcha para o oeste: $A$ epopeia da expedição Roncador-Xingu. São Paulo: Companhia das Letras.

WARnken, P. F. (1999). Política e programas: O setor da soja no Brasil. Revista de Política Agrícola, 8 (2), 1-45. https://seer.sede.embrapa.br/index.php/RPA/article/ view/692/646

WeSZ JR., V. J. (2014). O mercado da soja e as relações de troca entre produtores rurais e empresas no Sudeste de Mato Grosso (Brasil). Tese de doutorado em Ciências Sociais em Desenvolvimento, Agricultora e Sociedade. Rio de Janeiro: Universidade Federal Rural do Rio de Janeiro. 